\title{
POTENTIAL OF HBIM TO IMPROVE THE EFFICIENCY OF VISITOR FLOW MANAGEMENT IN HERITAGE SITES. TOWARDS SMART HERITAGE MANAGEMENT
}

\author{
E. Salvador-García ${ }^{1, *}$, M. J. Viñals ${ }^{1,2}$, J. L. García-Valldecabres ${ }^{1,2}$ \\ ${ }^{1}$ Universitat Politècnica de València, Valencia, Spain - elsalgar@doctor.upv.es; mvinals@upv.es; jgvallde@ega.upv.es \\ ${ }^{2}$ Research Centre PEGASO, Universitat Politècnica de València, Valencia, Spain
}

Commission II - WG II/8

KEY WORDS: HBIM, Heritage, Public visit management, Visitor management, Recreational carrying capacity, Touring pattern

\begin{abstract}
:
Providing public access to heritage promotes a social interest in its conservation but, at the same time, it poses a risk to the conservation of resources. The biggest challenge in managing public use of heritage is to establish a sustainable relationship between heritage and tourism. The multidisciplinary teams involved in visitor flow management generate and exchange information about the heritage property without an integrative vision. The lack of a reliable, unified and up-to-date source of information generally hinders decisionmaking, causes errors and leads to inappropriate practices in heritage visitor flow management, thereby putting the conservation of resources at risk because of the impacts derived from visitation while the quality experience is also affected. Building Information Modelling (BIM) provides a collaborative framework where multidisciplinary teams share geometric and documentary information about the building in a coordinated way. This tool applied to heritage (HBIM) is demonstrating how it is able to improve efficiency in documenting, intervening and managing heritage. Beyond these aforementioned skills, the objective of this study is to identify the potential of HBIM to improve the efficiency of the visitor flow management. The methodology includes a literature review, qualitative data collection and technical documentation analysis. The results indicate that the use of HBIM can optimise the planning and management of visitor flows, by virtually foreseeing the possible risks derived from visits. It can also calculate recreational carrying capacity and analyse alternatives to itineraries that minimise the deterioration of the most fragile spaces.
\end{abstract}

\section{INTRODUCTION}

The protection and conservation of cultural heritage has long been a major challenge for all peoples and nations (ICOMOS, 1999).

In the Athens Charter for the Restoration of Historic Monuments (1931), it was made clear that the best way to ensure the conservation of monuments arose from citizens' appreciation and respect for them, and therefore it recommended granting patrimonial assets a role that was useful for society. Other international charters have endorsed this recommendation and state that public use strengthens the links between society and the monument, while promoting social interest in its conservation ${ }^{1}$. For this reason, most heritage buildings are usually equipped for public visitation.

However, while tourism promotes social interest in heritage conservation, it also represents a challenge for the protection of the resources. For this reason, since the 1990s new techniques and tools have been developed to improve the sustainable management of the heritage and tourism dyad.

Visitor management is a process with a double objective: on the one hand, it is aimed at protecting heritage resources from the harmful impact of visitors and, on the other, at achieving visitor satisfaction. To achieve both objectives, García-Hernández (2003) proposes the implementation of the following consecutive actions: 1 . quantify and analyse the type of visitors; 2 . analyse

\footnotetext{
* Corresponding author

1 https://www.icomos.org/en/charters-and-texts/179-articles-enfrancais/ressources/charters-and-standards/187-guidelines-for-
}

mobility patterns and how visitors use the space; 3 . determine the Recreational Carrying Capacity; and 4. take steps to manage the visitor flow. In addition, to quantify the volume of flows, it is necessary to obtain data from visitor records and to carry out onsite counts (Calle Vaquero, García Hernández, 1998). Viñals et al. (2017) explain that the characterisation or profile of the visitors is obtained from data on their geographical origin, sociodemographic characteristics and aspects related to their expectations and motivations.

Once the number of visitors and their profile are known, it is necessary to analyse the mobility patterns and the use that the visitors make of the heritage space. In this way, it is possible to determine which areas are under greater pressure from tourism, where there are bottlenecks and which areas are underused. According to Manning and Lawson (2002), the Recreational Carrying Capacity is the maximum number of visitors accepted by a heritage space, beyond which the conservation of resources and the quality of the visitor's experience would be at risk. After years of research and study in this field, Viñals et al. (2017) have developed a process for determining the Recreational Carrying Capacity of natural and cultural resources. According to those authors, the process begins with the spatial analysis of the heritage resource and continues with the definition of the spatial needs of the visitors based on proxemic and recreational comfort standards. The Real Recreational Carrying Capacity is then determined by applying the limiting factors of the space itself in relation to the size and type of group and the number of visits per day. And finally, the Effective Recreational Carrying Capacity is calculated, taking 
into consideration the managing institution's own limiting factors. Once the Recreational Carrying Capacity has been established, it is necessary to take steps to manage the visitor flow in order not to exceed the preset limit. These steps include: restricting the number of visits, designing alternative itineraries and activities, determining the size of the group, rotating the visits, etc. All of these measures make it possible to decongest saturated spaces, channel the flow of visitors to underused spaces that are to be revalued, minimise the deterioration of the most fragile spaces and provide a better experience for the visitor.

Traditionally, the multidisciplinary teams involved in the management of public visits generate and exchange information about the heritage asset but do not have an integrated vision. Thus, the lack of a reliable, unified and updated source of information about the asset generally makes decision-making difficult, causes errors and leads to inappropriate management of the visit, which in turn jeopardises the protection of the resources and the quality of the visit.

In order to provide a solution to the problem of the low level of efficiency detected in the traditional heritage information management model, several organisations and researchers propose the use of the Heritage Building Information Modelling system (HBIM) (Maxwell, 2016; Dore, Murphy, 2017). It has been demonstrated that HBIM can improve the efficiency of heritage information management (Parisi et al., 2019), as it allows the geometric, semantic and documentary information on heritage properties from all disciplines involved to be centralised in a common repository and facilitates collaborative work and the coordinated exchange of information among multidisciplinary teams (Hawas, Marzouk, 2017).

A review of the literature on HBIM has shown that its information management capabilities can be successfully applied to document existing architecture (Hawas, Marzouk, 2017) and improve planning of restoration work (Bruno et al., 2018), maintenance (Fassi et al., 2016), management (Armisén et al., 2016) and dissemination of heritage (Barazzetti et al., 2015). However, no specific previous studies on the use of HBIM for visitor management have been found (Salvador-García et al., 2018), although some researchers have linked BIM models with pedestrian movement simulation software ${ }^{2}$ to develop evacuation plans for crowded places such as airports, shopping centres, etc. Such proposals could be easily transferred to analyse visitor behaviour and to plan visitor flows in historic buildings.

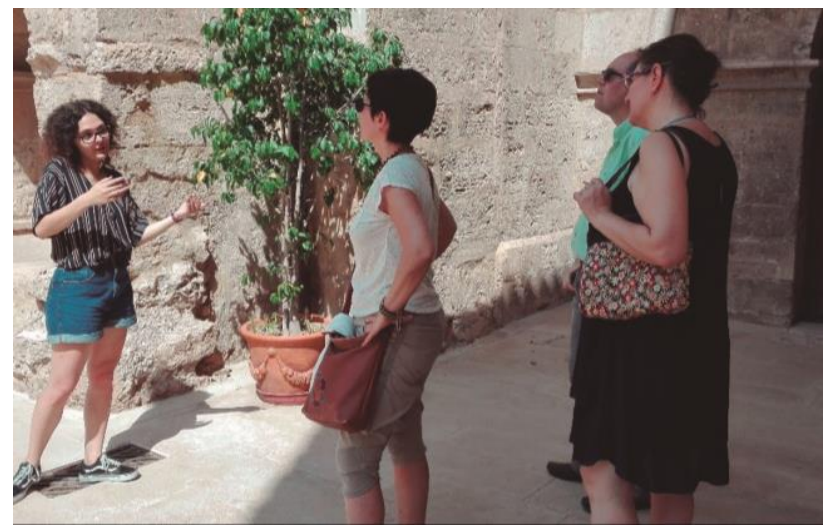

Figure 1. Public visit to San Juan del Hospital in Valencia. Source: Authors' own work.
Based on the work of Salvador-García et al. (2019a), where the potentialities of HBIM for the management of the public use of architectural heritage were identified, it is believed that the application of a smart model like HBIM, which increases the efficiency by the use of technology, can be considered a comprehensive quality tool within the framework of smart heritage management.

The aim of this article is to present the applications of HBIM to public visitation management and its implementation in a case study - that of the religious complex of San Juan del Hospital in Valencia (Figure 1).

This article is structured in four sections. In this introduction, the initial problem is set out and previous studies in the area of research are analysed to determine the gaps in current knowledge and to describe the specific objective of the study. The methodology section explains the rationale underlying the research method used, describes the case study selected, and explains the procedure followed in the study. The results and discussion section shows and interprets the findings. Lastly, the conclusions section shows the extent to which this study has contributed to science and proposes future lines of research.

\section{METHODOLOGY}

This study is part of a wider research project which aims to develop a protocol to help professionals implement HBIM in order to improve efficiency in the management of public visits to architectural heritage. The research method employed in this study is Design Science Research (DSR), which is used to develop an innovative device that solves a practical problem (Simon, 2006). Following the stages of the DSR proposed by Van Aken (2004), once the theoretical protocol has been developed, it is necessary to carry out a practical implementation of this protocol and then submit it to evaluation by a panel of experts.

This article shows the results of implementing the HBIM protocol for visitation management applied to the case study of San Juan del Hospital in Valencia.

The religious complex of San Juan del Hospital in Valencia dates from the 13th century. It was founded by the military and religious Order of Knights of the Hospital of Saint John after the reconquest of Valencia in 1238. It was the first Christian hospitalchurch in the city and the seat of the Order in Valencia. Originally the complex consisted of the church, the hospital, the cemetery and residential areas for the clergy. At present visitors can still see the church and two courtyards, one parallel to the nave of the church on the north side and the other on the south side, where the remains of the old mediaeval cemetery are located. It is a clear example of Mediterranean Gothic architecture and has been declared a Listed Building of Cultural Interest (in Spanish, BIC), classified as a Monument (Ayuntamiento de Valencia, 2010) and Museum (Generalitat Valenciana, 1997). It is privately owned and is used for both religious and public purposes. The Fundación de la Comunidad Valenciana Conjunto de San Juan del Hospital de Valencia (San Juan del Hospital Foundation) is responsible for managing public visitation. Although overtourism is not currently a problem, the owners have shown an interest in applying the HBIM system to improve the public visitation management.

\footnotetext{
2 https://www.oasys-software.com/case-studies/stadium-fireevacuation-planning/ (22 June 2018)
} 
It was applied to the case study in accordance with the following phases: 1. Preparation of the HBIM model, 2. HBIM modelling of the complex, and 3. Application of the HBIM protocol for the management of visitors to the case study. The entire implementation process was carried out in collaboration with the architectural studio specialised in BIM, Salva Moret Architecture + BIM studio.

\subsection{Preparation of the HBIM model}

The starting point for the practical implementation was a previous HBIM model of the San Juan del Hospital complex, developed as a result of the research project financed by the Spanish Ministry of Economy and Competitiveness (GarcíaValldecabres et al., 2016) and extended by the master's degree theses of Jordán-Palomar (2015), Forero (2018) and Mogena (2018). This HBIM model was created with Autodesk Revit software from a point cloud obtained using the laser scanner technique. This model contained the modelling of the geometry and information about the south courtyard, church and chapel of Santa Barbara, construction phases, archaeological remains, heritage families and heritage template.

Because this previous model had been developed by different professionals at different times and for different purposes, there was no single working criterion and it was necessary to homogenise the model so that it could later be implemented. The first task in preparing this model was to decide which links were permanently connected to the main model and which would be maintained as external links. Secondly, overlapping or duplicated elements were removed and finally the categorisation of the Revit elements was unified.

\subsection{HBIM modelling of the complex}

Once the initial HBIM model was ready and in order to have a complete HBIM model, the geometry of the rest of the complex was modelled, i.e. the entrance passageway, north courtyard, museum hall and adjacent buildings. The complete HBIM model was created with the same Revit software from a point cloud obtained using the laser scanner technique.

\subsection{Implementation of the HBIM protocol for the management of visitors to the case study}

After the HBIM modelling of the rest of the complex, the visitor management needs were defined, the structuring of the information was studied and the specific information required for visitor management was incorporated in order to obtain the following results: 1) Identification and assessment of tourist landmarks; 2) Design of the tourist itinerary; 3) Determination of the Recreational Carrying Capacity.

\subsection{Identification and assessment of tourist landmarks}

In order to identify the main tourist attractions or landmarks, the "generic model" category of Revit was used; thus, they were represented with a "location pin" and placed at the ideal point for viewing the landmark.

New parameters ("accessible", "visitable") and the criteria of intrinsic value and tourist value proposed by Viñals et al. (2017) were added to each landmark. The intrinsic assessment criteria used were: significance, representativeness, singularity, integrity, authenticity and contextualisation. The tourism evaluation criteria were: attractiveness, resistance, availability, on-site accessibility, feasibility, educational values and functionality.
The criteria for each landmark were rated using a 1-5 Likert-type scale and a colour code covering a range of intensities. This colour code was assigned depending on the rating, the most intense being the one with the highest value. This made it possible to visualise the landmarks on a 2D plan and to highlight those that had the greatest tourist value (Figure 3). In addition, a list of tourism landmarks was generated for each of the Spatial Units (SUs) identified through planning tables.

\section{RESULTS AND DISCUSSION}

As mentioned above, in order to implement the protocol in the case study, a previous HBIM model was used, the overlapping elements were removed and the categorisation of the elements was unified. Subsequently, the HBIM modelling of the rest of the complex was completed (Figure 2).

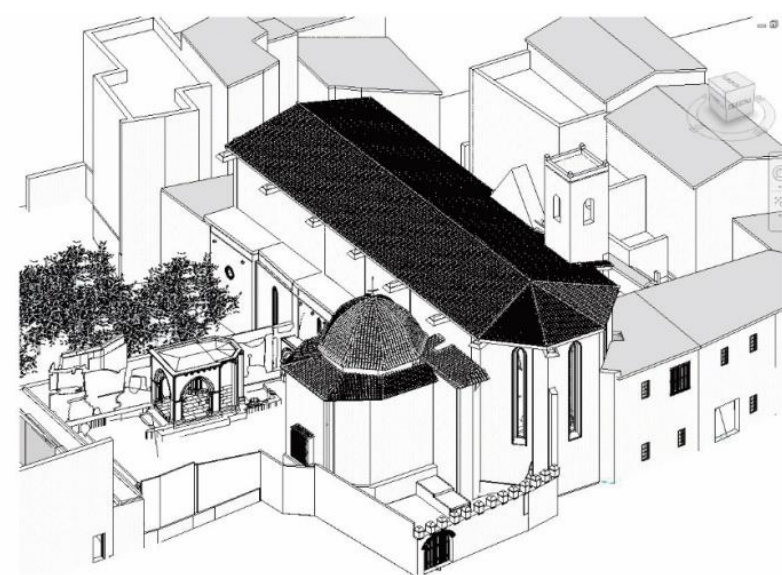

Figure 2. HBIM model of San Juan del Hospital in Valencia. (Source: Salvador-García, et al., 2019b).

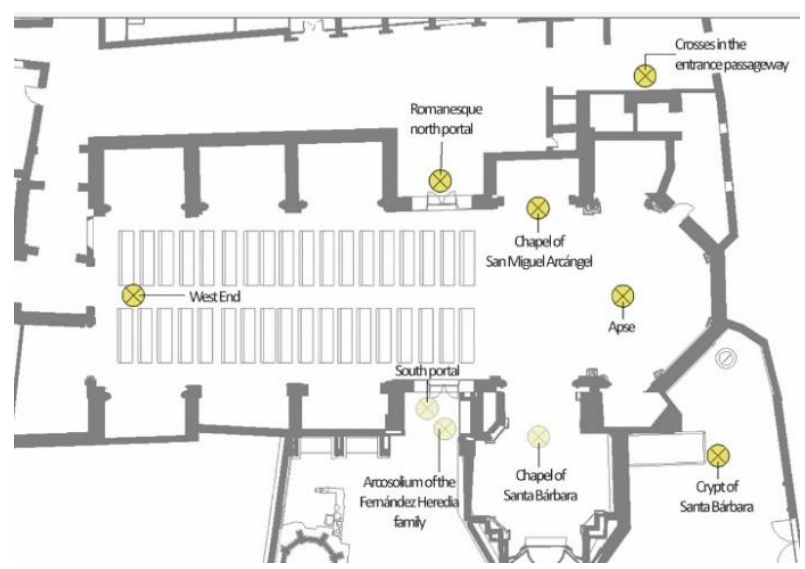

Figure 3. 2D view highlighting the resources with the highest attraction value. Source: Authors' own work.

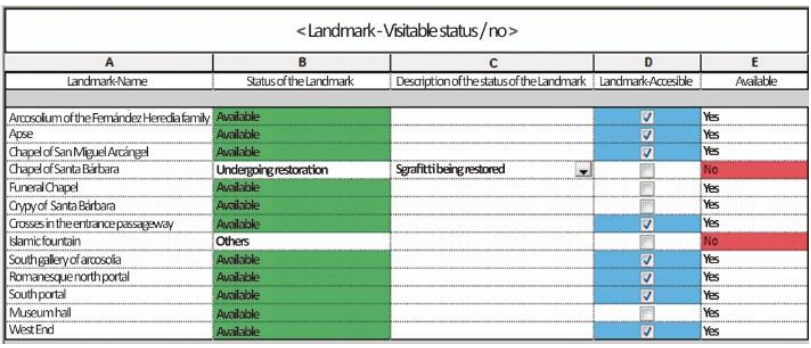

Figure 4. Table showing the availability of tourist landmarks for visits. Source: Authors' own work. 
Since the tourist landmarks (elements and spaces) are not always available for visitation, a new "yes/no" parameter was generated and the reason for their non-availability was indicated as "on loan", "being restored", "other temporary use", "for research purposes" and "other". A "comments" field was also added. This allowed a list of available landmarks to be generated along with a description of the reasons for the cases of non-availability (Figure 4).

To facilitate the 3D visualisation and location of tourist landmarks, they were highlighted with shading. As can be seen in Figure 5, by way of example, the arcosolia are a tourist landmark and for this reason they are shaded. However, the Islamic fountain, marked with a broken line, despite having a high tourist value in terms of "attractiveness", is currently not available for visits and therefore has an "availability" rating of zero and for that reason it has not been shaded.

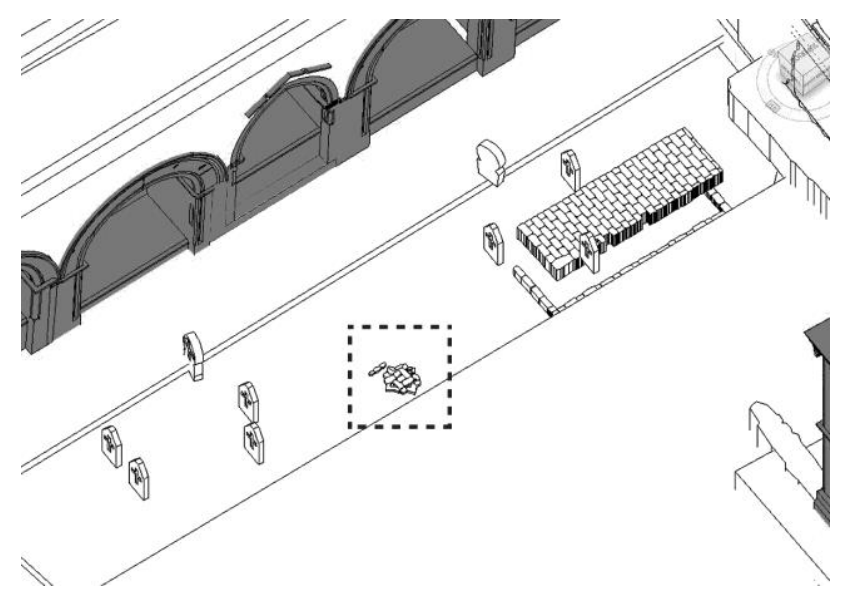

Figure 5. 3D view highlighting the tourist landmarks. Source: Authors' own work.

\subsection{Design of the tourist itinerary}

The itinerary of the visit was created with a generic model similar to the one used to represent the fire evacuation route of the buildings. The itinerary covers the most outstanding tourist landmarks that are available, for a visit that lasts, on average, 1 hour (Figure 6).

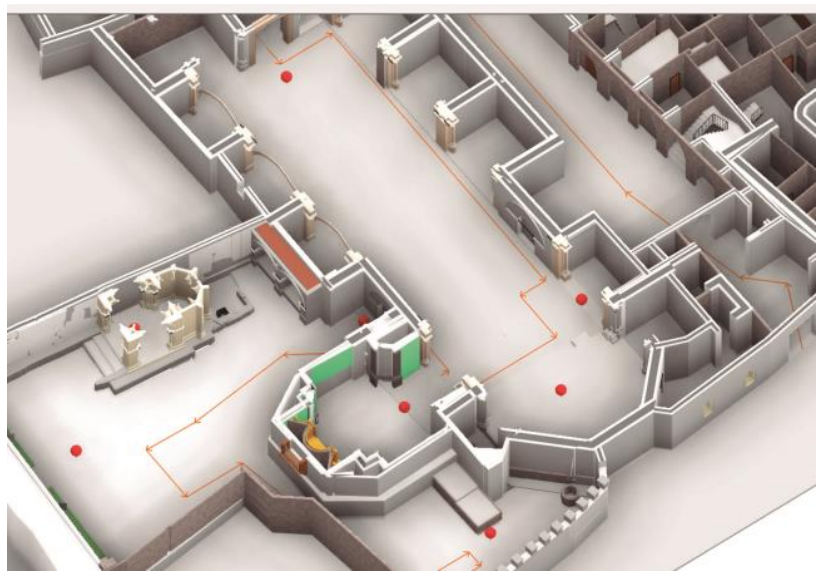

Figure 6. 3D view of the tourist itinerary. Source: Authors' own work.

\subsection{Determination of the Recreational Carrying Capacity}

To determine the Recreational Carrying Capacity, the following steps were carried out: zoning of usage, identification of the different SUs according to their physical characteristics, determination of the available or Usable Surface Area for Recreation (USAR) of the SUs and, lastly, calculation of the Recreational Carrying Capacity.

The uses of the rooms were zoned using the "Area" category of Revit because it is the most appropriate to delimit different uses of the same space when they are not divided by physical construction assemblies. Three uses were differentiated: "public visitation", "circulation area" and "non-visitable". These were distinguished by a colour code and the specific use of each space was detailed: "religious use", "private use", "occasional cultural use", "administrative use" and "toilets", with an indication of the compatibility of uses of the different spaces.

The "Room" category of Revit was used to zone the SUs, since it makes it possible to assign a use and associate the tourist landmarks contained in each SU. This category also allows the assignment of area, perimeter and volume properties, which are fundamental aspects for the calculation of the Recreational Carrying Capacity and the parameters involving the finishes of the floor, ceiling, walls, etc. This can be very useful for recording the current state of conservation and planning the preventative conservation programme. The incorporation of this information regarding the Spatial Units allowed a zoning plan to be generated for the five SUs of the complex, i.e. entrance passageway, north courtyard, museum hall, church and south courtyard, which are differentiated by a colour code. The plan also shows their usable areas (Figure 7).

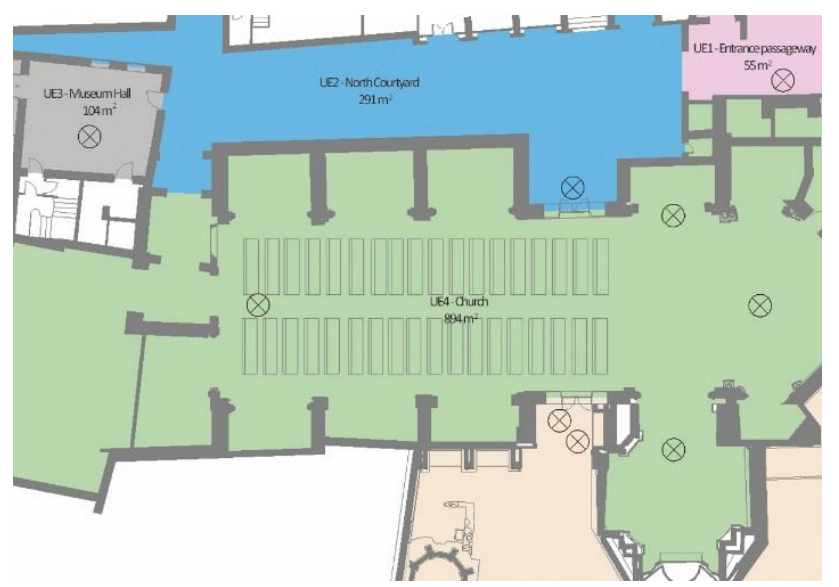

Figure 7.2D plan of the Spatial Units.

Source: Authors' own work.

The next step in calculating the Recreational Carrying Capacity was to determine the Usable Surface Area for Recreation (USAR), which is the area available for public visitation after subtracting the Non-Usable Surface Area for the Recreation (NUSAR) from the Spatial Units. The NUSAR consists of the surfaces that cannot be used for public visitation for various reasons: conservation, fragility, security, incompatibility of uses or because of the spatial arrangement of internal components (furniture, columns, etc.). These spaces, given that they are not limited by construction assemblies, were delimited using the "Area" category of Revit. 
To delimit the NUSAR, an area parallel to the old walls was delimited for " conservation reasons" in order to minimise the risks of wear and tear that could be caused by public visitation. In addition, the most fragile surfaces were identified: the arcosolia in the south courtyard, the painted murals in the Chapel of San Miguel Arcángel, the pavement in the funeral chapel and the sgraffiti in the Chapel of Santa Bárbara. The spaces that presented limitations due to "security reasons" were the primitive chapel of Santa Bárbara and the crypt of Santa Bárbara. The areas of circulation and the spaces between the ideal viewpoints for observing the landmarks and the landmarks themselves were considered to be spaces incompatible with the transit of people. This makes it possible to avoid obstructions or intrusions in the viewshed. Finally, the pews in the church and the altars of the side chapels were considered "internal layout of components" limiting public visitation usage (Figure 8).

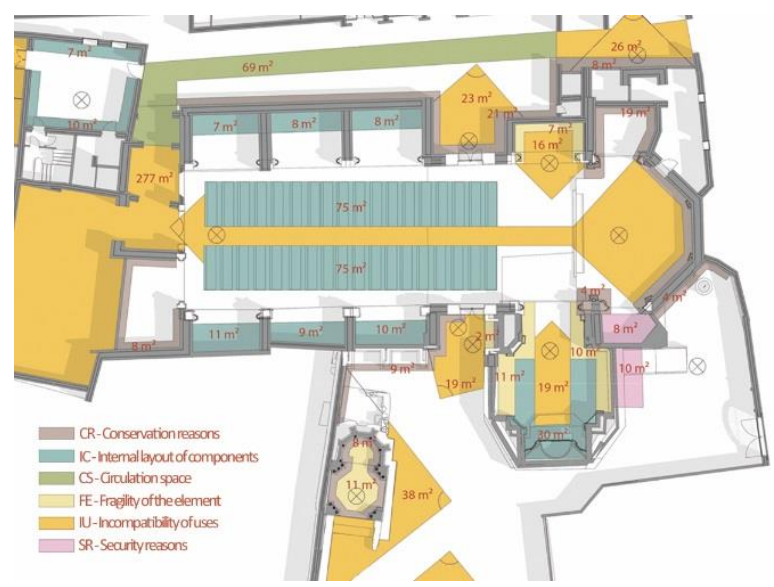

Figure 8. Plan of non-usable surface areas for recreation. Source: Authors' own work.

Once the USAR and NUSAR had been defined, a definition was developed in Dynamo, which relates the two areas and allows the USAR of each SU to be extracted to an Excel spreadsheet. All the mathematical operations needed to calculate the Recreational Carrying Capacity were added to this Excel file.

The division between the USAR and the personal proxemic standard (interpersonal interaction space when carrying out a group activity) made it possible to calculate the number of people in each SU that can perform the activity at the same time (people at one time - PAOT) under conditions of physical and psychological comfort. The proxemic standard used to carry out a group activity in closed spaces is $1.2 \mathrm{~m}^{2}$, and for open spaces, $1.5 \mathrm{~m}^{2}$, following Hall's proposals (1982). Thus, the ideal group size that has been established for visits in this religious complex is 12 people, bearing in mind the characteristics of the heritage site and the religious role that it shares with public visitation.

To calculate the number of groups that can be present simultaneously in each SU, the PAOT was divided by the size of the group (12 people) and the limiting factor Minimum permissible distance was applied between groups to ensure visual and acoustic comfort during visits. Based on practical experience in the development of tourist routes and itineraries, 25 metres is taken as the minimum reference distance between groups in closed spaces and 50 metres in open spaces. This calculation has shown that the most unfavourable space to accommodate several groups simultaneously is the Museum Hall; for this reason, it has been determined that there can be only one group per SU at the same time.
To calculate the coefficient of group turnover on the same day, the available visiting hours (open 4 hours per day) were divided by the average duration of the activity ( 1 hour). This operation resulted in a minimum turnover rate of four visits per day. However, bearing in mind the spatial configuration of the building, it is also possible to have several groups at the same time and schedule two visits per hour, which leave with a difference of 30 minutes between one group and the next, or even three visits per hour, starting every 20 minutes. This would give a total of 4,8 or 12 visits per day under physically and psychologically comfortable conditions.

Lastly, the final Recreational Carrying Capacity was calculated by multiplying the number of simultaneous groups and the turnover coefficient. In this case study, since the number of simultaneous groups is 1 , the size of the group is 12 people and the turnover coefficient is 4,8 and 12 , the most unfavourable Recreational Carrying Capacity would be 144 visitors per day. It should be noted that a detailed study of the possible impacts that this volume of visitors might cause would be necessary to refine this estimate.

\section{CONCLUSIONS}

The results obtained in this study have demonstrated, for the first time, that HBIM can be a useful tool with which to analyse, plan and manage the public visits to heritage assets in a more efficient manner, since it facilitates the decision-making of the agents involved.

In relation to the planning of visitor flows, the results of this study indicate that the spatial capabilities of HBIM, that is, the possibility of identifying and assessing tourist landmarks and relating them spatially and temporally facilitates decisionmaking when it comes to designing the tourist itinerary, determining the size of the group and the rate of turnover of the visits, planning the coordination of simultaneous itineraries, etc. Although the itinerary has been carried out manually, future studies aim at achieving further automation of the offer of alternative itineraries based on the availability of visitable resources, the order of visitation and the total time of the visit.

The capability of HBIM to analyse different alternatives virtually can detect and solve problems arising from the harmful impact of visitors before they are implemented, thus reducing the time and cost to be invested in order to achieve a more sustainable visitation management.

The results of this study also indicate that HBIM facilitates the calculation of the Recreational Carrying Capacity, since, although it can be determined using other traditional tools, HBIM handles spatial information more efficiently and allows the linking of semantic information so that it can be determined in a more comprehensive manner.

The results presented in this article are considered a good starting point in Smart Heritage Management. In addition, the authors have also identified lines for future research focused on real-time visitation management based on the combination of sensors and GPS devices with HBIM models. This real-time information anticipates situations of congestion and facilitates traffic alternatives to avoid visitor saturation and discomfort. Furthermore, HBIM could allow the integrated management of information from different properties with the same ownership, for example, for the development of thematic routes that relate properties with common characteristics. 


\section{ACKNOWLEDGEMENTS}

The authors wish to thank Salva Moret Architecture + BIM studio for their collaboration in the implementation of the case study.

\section{REFERENCES}

Armisén, A., García-Fernández-Jardón, B., Mateos, F.J., Valdeón, L., Rojo, A., 2016: Plataforma virtual para el diseño, planificación, control, intervención y mantenimiento en el ámbito de la conservación del patrimonio histórico «PetroBIM». Congreso Euro-Americano REHABEND 2016, 1-8.

Ayuntamiento de Valencia, 2010: Catálogo de bienes y espacios protegidos. Templo y dependencias de San Juan del Hospital.valencia.es/ayuntamiento/urbanismo.nsf/vDocumentos TituloAux/Portada\%20CON\%20columna\%20de\%20apoyo?ope ndocument\&lang=1\&nivel=1 (13 January 2020).

Barazzetti, L., Banfi, F., Brumana, R., Oreni, D., Previtali, M., Roncoroni, F., 2015: HBIM and augmented information:towards a wider user community of image and range-based reconstructions. The International Archives of the Photogrammetry, Remote Sensing and Spatial Information Sciences, XL-5/W7, 35-42.

Bruno, S., De Fino, M., Fatiguso, F., 2018: Historic Building Information Modelling: performance assessment for diagnosisaided information modelling and management. Automation in Construction, 86, 256-276.

Calle Vaquero, M. de la, García Hernández, M., 1998: Fuentes y técnicas para el estudio del turismo en las ciudades históricas. Ería, 47, 326-333.

Sociedad de Naciones, 1931: Carta de Atenas. ipce.culturaydeporte.gob.es/conservacion-y-

restauracion/documentos-nacionales-internacionales

September 2018).

Dore, C., Murphy, M., 2017: Current state of the art historic building information modelling. The International Archives of the Photogrammetry, Remote Sensing and Spatial Information Sciences, XLII-2/W5, 185-192.

Fassi, F., Mandelli, A., Teruggi, S., Rechichi, F., Fiorillo, F., Achille, C., 2016: VR for Cultural Heritage A VR-WEB-BIM for the Future Maintenance of Milan's Cathedral. In: L.T. De Paolis and A. Mongelli (ed.), International Conference on Augmented Reality, Virtual Reality and Computer Graphics, 139-157. Springer International Publishing Switzerland, Cham.

Forero, D., 2018: Mejora del modelo Historic Building Information Modeling (HBIM) para la gestión de fases históricoconstructivas. Aplicación al caso de la nave de la iglesia de San Juan del Hospital en Valencia. Unpublished.

García-Hernández, M., 2003: Turismo y conjuntos monumentales:capacidad de acogida turística y gestón de flujos de visitantes. Tirant lo Blanch, Valencia.

García-Valldecabres, J., López-González, M.C., SalvadorGarcía, E., March, R., Jordán-Palomar, I., 2016: El diseño de una base de datos, modelo para la gestión de la información y del conocimiento del Patrimonio Arquitectónico. Unpublished.
Hall, E.T., 1982: The hidden dimension. Anchor Books Editions, New York.

Hawas, S., Marzouk, M., 2017: Integrating Value Map with Building Information Modelling Approach for Documenting Historic Buildings in Egypt. In: Y. Arayaci, J. Counsell, L. Mahdjoubi, G. Nagy, S. Hawas y K. Dewidar (eds.), Heritage Building Information Modelling, 62-72. Routledge. Taylor\& Francis Group, London \& New York.

ICOMOS, 1999: Carta Internacional sobre Turismo Cultural. icomos.org (13 September 2018)

Jordán-Palomar, I., 2015: Metodología HBIM; Diseño de un método para la gestión de la información y el conocimiento del patrimonio arquitectónico medieval aplicado al Conjunto de San Juan del Hospital de Valencia. Unpublished.

Manning, R.E., Lawson S.R., 2002: Carrying Capacity as "Informed Judgment": The Values of Science and the Science of Values. Environmental Management, 30 (2), 157-168.

Maxwell, I., 2016: COTAC BIM4C Integrating Report Part 1: Conservation Parameters.

Mogena, R., 2018: Diseño de un protocolo para la definición LOD en HBIM. Aplicado a la Capilla de Santa Bárbara de San Juan del Hospital en la ciudad de Valencia. Unpublished.

Parisi, P., Turco, M., Giovanni, E.C., 2019: The value of knowledge through H-BIM models: Historic documentation with a semantic approach. The International Archives of the Photogrammetry, Remote Sensing and Spatial Information Sciences, XLII-2/W9, 581-588.

Salvador-García, E., García-Valldecabres, J., Viñals Blasco, M.J., 2018: The use of HBIM models as a tool for dissemination and public use mangement of historical architecture: a review. International Journal of Sustainable Development and Planning 13(1), 96-107.

Salvador-García, E., García-Valldecabres, J., Viñals Blasco, M.J., 2019a: Integrating HBIM models in the management of the public use of heritage buildings. Canadian Journal of Civil Engineering, 47(2), 228-235.

Salvador-García, E., García-Valldecabres, J., Viñals, M.J., Moret, S. 2019b: Heritage Building Information Modelling (HBIM) como herramienta para la gestión del uso público del patrimonio arquitectónico. EUBIM, 35-46. Editorial Universitat Politècnica de València, Valencia.

Simon, H.A., 2006: Las ciencias de lo artificial. Comares Editorial, Granada.

Van Aken, J.E., 2004: Management research on the basis of the design paradigm: The quest for field-tested and grounded technological rules. Journal of Management Studies, 41(2), 219246.

Viñals, M.J., Mayor, M., Martinez-Sanchis, I., Teruel, L., Alonso-Monasterio, P., Morant, M., 2017: Turismo sostenible y patrimonio: herramientas para la puesta en valor $y$ planificación. Editorial Universitat Politècnica de València, Valencia. 